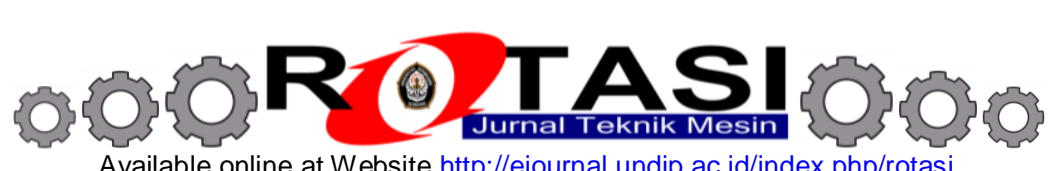

Available online at Website http://ejournal.undip.ac.id/index.php/rotasi

\title{
IDENTIFIKASI MATERIAL DAN KERUSAKAN DISC REFINER AIRAGHI DI PT. PURA NUSA PERSADA UNIT PAPER MILL 8 KUDUS
}

\author{
*Bakti Sofyarto, Athanasius Priharyoto Bayuseno, Sri Nugroho \\ Program Studi Magister Teknik Mesin, Fakultas Teknik, Universitas Diponegoro \\ Jl. Prof. Sudharto, SH., Tembalang-Semarang 50275, Telp. +62247460059 \\ *E-mail: bsofyarto73@gmail.com
}

\begin{abstract}
ABSTRAK
Refining adalah proses penggilingan bubur serat lanjut untuk menghasilkan bubur serat yang lebih halus. Setelah itu bubur serat tersebut diolah kembali dengan cara dipotong dan digiling dengan menggunakan 2 buah pisau pemotong yang berbentuk bilah plat (disc plate atau disc refiner). Masalah yang dihadapi pada proses refining adalah kegagalan pada pisau disc refiner akibat proses abrasif dan keausan.

Tujuan penelitian ini adalah melakukan identifikasi material disc refiner yang digunakan, studi metallografi terhadap material disc refiner yang digunakan, menentukan dan mencari penyebab terjadinya kerusakan pada disc refiner ,memberikan rekomendasi pada perusahaan mengenai disc refiner yang terbaik.

Diperlukan pengujian dari yang paling sederhana sampai diperlukan alat yang canggih mulai dari uji percik dengan melihat percikan material, pengamatan struktur micro, mencari tahu besarnya kekerasan dan kandungan komposisi kimia yang terdapat pada material dan selanjutnya dibandingkan dengan data pembanding standar.

Hasil penelitian menyimpulkan bahwa dari disc refiner airaghi yang dipakai di unit paper mill 8 merupakan material Stainless steel UNS S41000, dengan kerusakan seperti serration dan deformasi platis. Pemilihan pola disc refiner yang disesuaikan dengan kondisi pulp, di PT PNP PM 8 Kudus yang cocok adalah menggunakan pola dengan 3 bagian Breaker bar, Intermediate bar dan Fine bar.
\end{abstract}

Kata Kunci: disc refiner, material, paper mill, stainless steel.

\section{PENDAHULUAN}

Pertumbuhan industri bubur kertas (pulp) dan kertas di Indonesia sungguh menakjubkan. Indonesia menempati peringkat ke 9 produksi pulp dunia, dengan pangsa 2,5\% dari total produksi dunia yang mencapai 200 juta ton. Sedangkan produksi kertas Indonesia menduduki peringkat ke-12 dunia, dengan pangsa 2,2\% dari total produksi dunia yang mencapai 350 juta ton. Adapun pulp dan kertas produksi Indonesia diperkirakan tetap menguasai 2,5\% pasar dunia pada tahun 2011. Kebutuhan kertas dunia pada tahun 2011 ditaksir mencapai 350 juta ton dan pulp 200 juta ton (www. duniaindustri.com, 2011)

Untuk menopang kemajuan di industri kertas dan pulp harus didukung oleh sarana produksi (mesin-mesin) yang handal dan bahan baku yang cukup. Kendala yang dihadapi dengan masih banyaknya suku cadang yang impor adalah terganggunya proses produksi. Karena jika ada kerusakan dan suku cadang di pabrik habis maka harus menunggu hingga beberapa minggu untuk mendatangkan suku cadang yang diperlukan. Hal inilah yang saat ini banyak menjadikan masalah di industri-industri kertas.

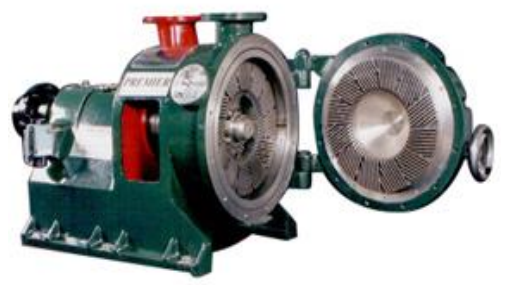

Gambar 1. Mesin refining

Berhentinya proses produksi akan berakibat pada tidak terpenuhinya kapasitas produksi dan berujung tidak terpenuhinya target produksi. Penerapan permesinan dan bagian-bagiannya yang cocok untuk proses produksi yang berjalan berkesinambungan dan tiap bagiannya saling berkaitan sangatlah dibutuhkan. Salah satu mesin yang sering mengalami unscheduled down time atau kegagalan beroperasi di industri kertas adalah pada bagian proses refining. Refining adalah proses penggilingan bubur serat lanjut untuk menghasilkan bubur serat yang lebih halus. 
Setelah itu bubur serat tersebut diolah kembali dengan cara dipotong dan digiling dengan menggunakan 2 buah pisau pemotong yang berbentuk bilah plat (disc plate atau disc refiner). Masalah yang dihadapi pada proses refining adalah kegagalan pada pisau disc refiner akibat proses abrasif dan keausan (Gambar 1).

Tujuan yang hendak dicapai dalam penelitian ini adalah melakukan identifikasi material disc refiner yang digunakan, menentukan dan mencari penyebab terjadinya kerusakan pada disc refiner dan memberikan rekomendasi pada perusahaan mengenai disc refiner.

Penelitian yang telah dilakukan oleh beberapa peneliti sebelumnya adalah Jia Yuding (1996) melakukan penelitian pada bagian permukaan disc refiner thermomechanical pulping, dengan melakukan pengujian C20 (20-2-1) iron \& S17 (440C) Stainless steel, J\&L Fiber Service vol V no 1 (-) melakukan penelitian dengan membandingkan disc refiner C90 dan 17-4 PH, dari segi pengaruh keausan lama pemakaian dan J\&L Fiber Service vol II no 2 (-) melakukan penelitian dengan membandingkan disc refiner yang diberi perlakuan heat treatment dengan dan tanpa diberi perlakuan heat treatment berbahan white iron $2,8 \%$ carbon dan stainless steel $1 \%$ carbon, dari segi pengaruh keausan, ketahanan kavitasi dan ketahanan patah.

\section{MATERIAL DAN METODOLOGI}

Disc refiner yang diamati untuk penelitian ini diambil dari PT. PURA NUSA PERSADA Unit Paper Mill 8 dengan merk Airaghi buatan Italia.

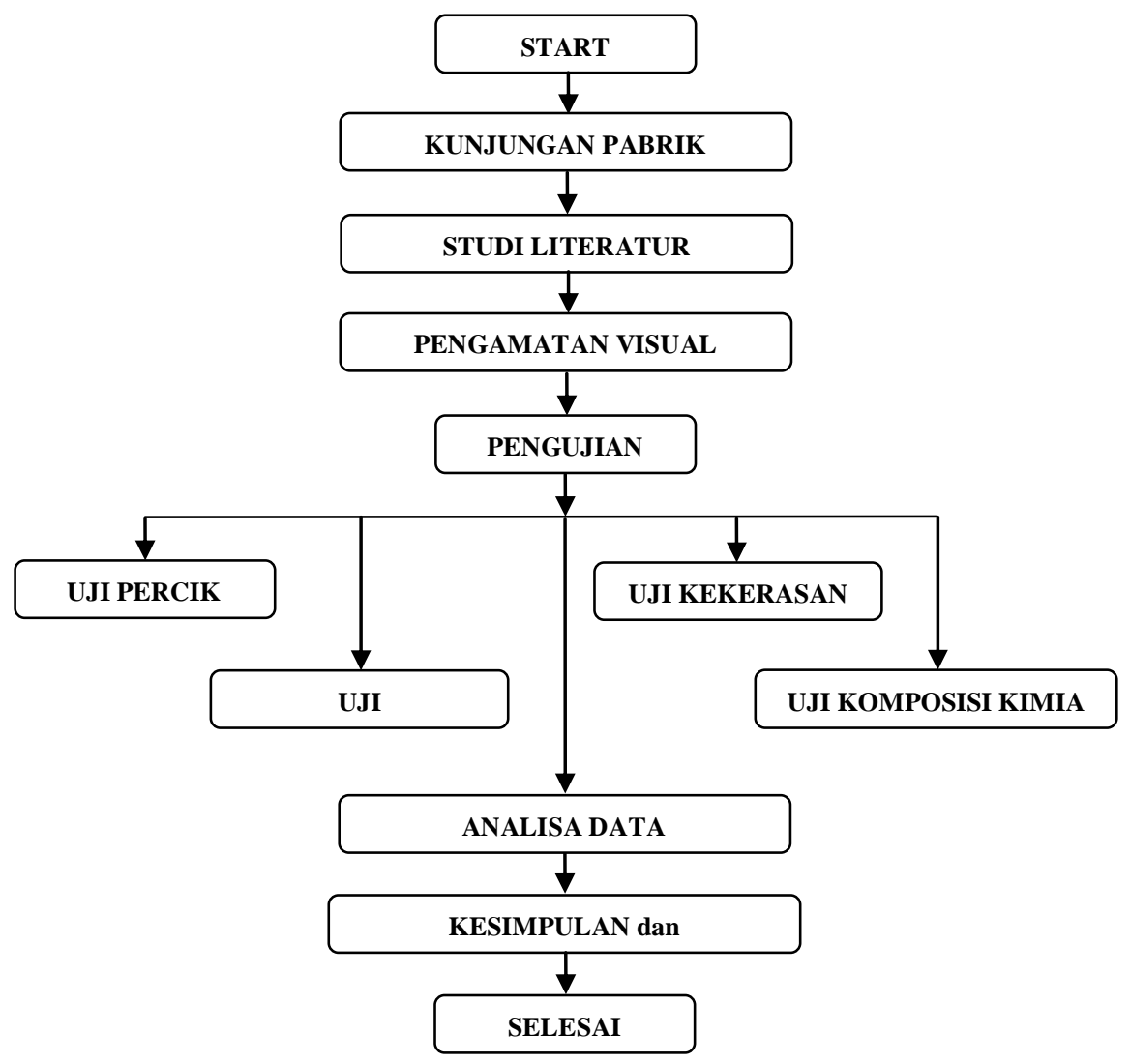

Diperlukan pengujian dari yang paling sederhana sampai diperlukan alat yang canggih mulai dari uji percik dengan melihat percikan material, pengamatan struktur micro, mencari tahu besarnya kekerasan dan mencari tahu kandungan yang terdapat pada material yang selanjutnya dibandingkan dengan data pembanding standar.

\section{HASIL DAN PEMBAHASAN}

Hasil penelitian yang telah dilakukan pada material yang diambil dari perusahaan

3.1. Bentuk Fisik disc refiner Airaghi

Berdasarkan pengamatan bentuk fisik disc refiner Airaghi secara langsung (visual) (Gambar 2) didapatkan kondisi bahwa disc refiner ini full segmen, dengan permukaannya hanya terdapat pola fine bar, penampilan material tanpa di beri perlakuan berwarna putih mengkilat atau berwarna perak, jika dibandingkan dengan berat besi sama beratnya (The welding handbook, -) dan dipukul untuk didengarkan suara resonansi yang dihasikan didapatkan suara tinggi kesimpulan sementara material disc refiner Airaghi merupakan material stainless steel . 


\subsection{Sifat Percikan Logam}

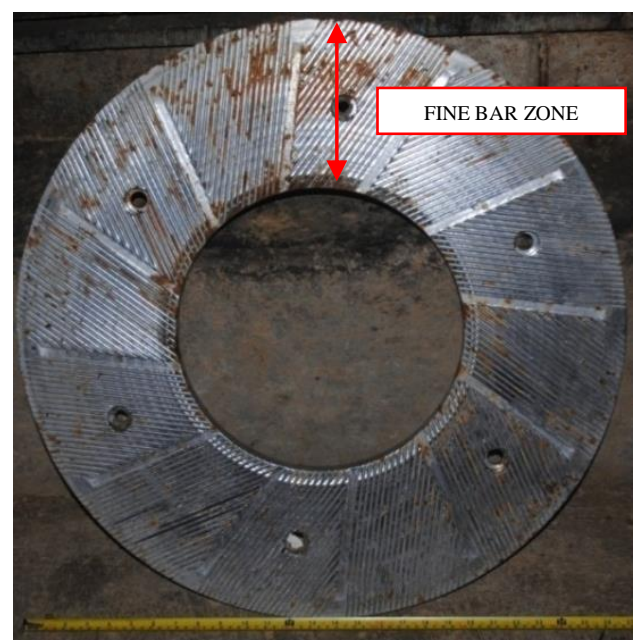

Gambar 2. Penampang disc refiner Airaghi

Berdasarkan pengujian percikan logam (spark test) $\quad$ (Gambar 3$)$ untuk material disc refiner Airaghi didapatkan serpihan/ loncatan bunga api gerinda menunjukkan loncatan panjang, ujung serpihan memanjang dan berwarna kuning cerah kesimpulan sementara material ini stainless steel (The welding handbook, -).

\subsection{Pengujian kekerasan}

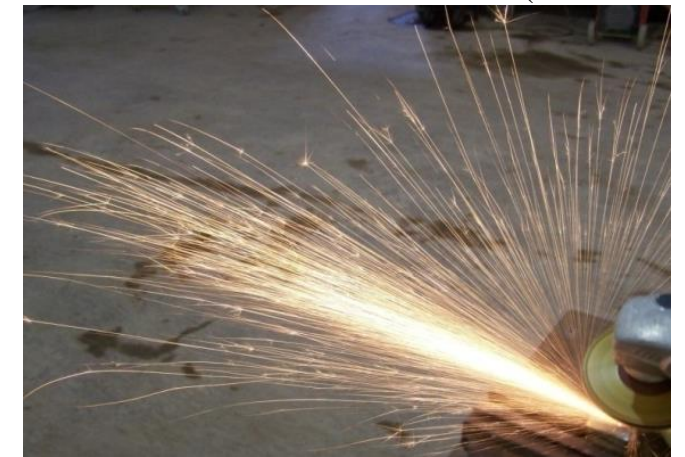

Hasil pengujian kekerasan specimen didapatkan kekerasan 50,75 HRC atau setara dengan 524,3 HV.

\subsection{Pengujian Komposisi}

Diambil beberapa bagian yang menunjukkan kondisi komposisi mendekati sama

Tabel 1. Komposisi kimia disc refiner Airaghi dengan pembanding

\begin{tabular}{|c|l|l|}
\hline & Komposisi Uji & Komposisi ASM \\
\hline NAMA & \multicolumn{1}{|c|}{ Sampel } & UNS S41000 \\
\hline $\mathrm{C}$ & 0,169 & 0,15 \\
\hline $\mathrm{Cr}$ & 12,6 & $11,5-13,5$ \\
\hline $\mathrm{Ni}$ & 0,281 & - \\
\hline $\mathrm{Cu}$ & 0,084 & \\
\hline $\mathrm{Si}$ & 0,294 & 1,00 \\
\hline $\mathrm{Mn}$ & 0,885 & 1,00 \\
\hline $\mathrm{S}<$ & 0,005 & 0,03 \\
\hline $\mathrm{Mo}$ & 0,00259 & \\
\hline $\mathrm{Al}$ & 0,0309 & \\
\hline $\mathrm{Co}$ & 0,0244 & \\
\hline & &
\end{tabular}




\begin{tabular}{|c|l|l|}
\hline $\mathrm{P}<$ & 0,005 & 0,04 \\
\hline $\mathrm{Nb}$ & 0,0485 & \\
\hline $\mathrm{Ti}$ & 0,0203 & \\
\hline $\mathrm{V}$ & 0,0294 & \\
\hline $\mathrm{W}<$ & 0,025 & \\
\hline $\mathrm{Pb}$ & 0,0582 & 0,0582 \\
\hline
\end{tabular}

Berdasarkan komposisi kimia yang telah dilakukan pada material disc refiner Airaghi didapatkan kesimpulan dari komposisi kimia bahwa, material ini merupakan wrought Martensite stainless steel dengan seri ASM 410, CA 15M kelas A (Properties Materials ASM, vol 1) (ASTM A 487).

\section{Sifat Material}

Tensile strength

Yield Strength

Elongation

: 620-795 MPa

Reduction area

$$
\begin{aligned}
& : 450 \mathrm{MPa} \\
& : 18 \% \\
& : 30 \%
\end{aligned}
$$

\subsection{Pengujian Struktur Mikro.}

Berdasarkan hasil uji struktur mikro didapatkan gambar butir sbb

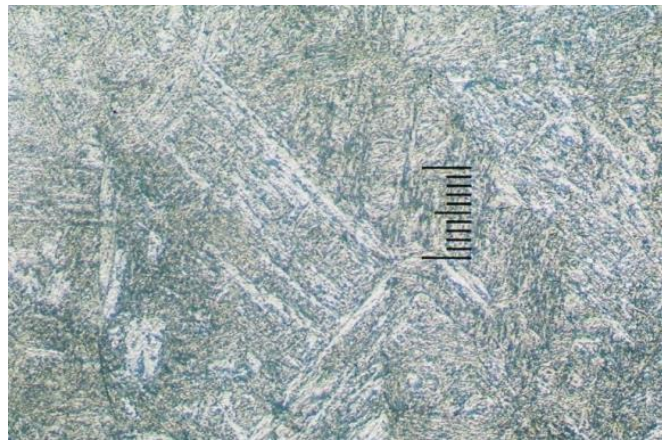

Gambar 4. Metalografi disc refiner Airaghi hasil pengujian specimen

Dari hasil pengujian struktur mikro didapatkan bentuk butiran lath martensite stainless steel

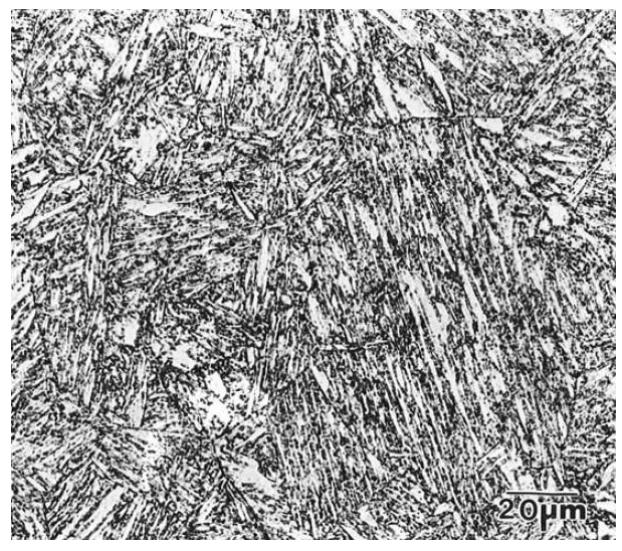

Gambar 5. Metalografi standart SAE 410 Martensit Stainless steel. Vilella's etch 500x (K.Luer, Lehigh University, Bruce L, ASM vol 1, 2002)

\subsection{Pengamatan Visual Kondisi Disc Refiner Airaghi yang Mengalami Kegagalan.}

Kerusakan disc refiner Airaghi ini (Gambar 6 \& 7) jika dilihat melalui pengamatan secara langsung adalah jenis Serration dan deformasi plastis. 


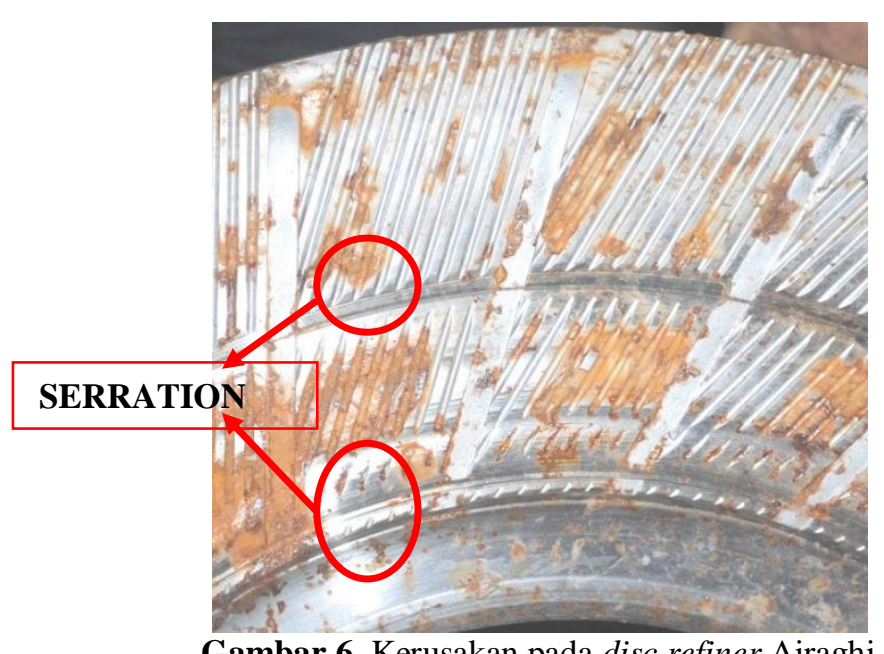

Gambar 6. Kerusakan pada disc refiner Airaghi

Dilihat dari penampilan posisi alur disc refiner yang hanya mempunyai bagian Fine bar, setelah pulp masuk melalui bagian tengah dilanjutkan ke bagian terluar dari disc, sehingga hal ini dimungkinkan akan terjadi kerusakan di bagian tengah fine bar karena beban yang berat, pulp hanya dilakukan perlakuan langsung pada disc refiner. Kecenderungan kerusakan terparah pada bagian masuk dari pulp pada sisi disc refiner sampai bagian tengah dari disc refiner.

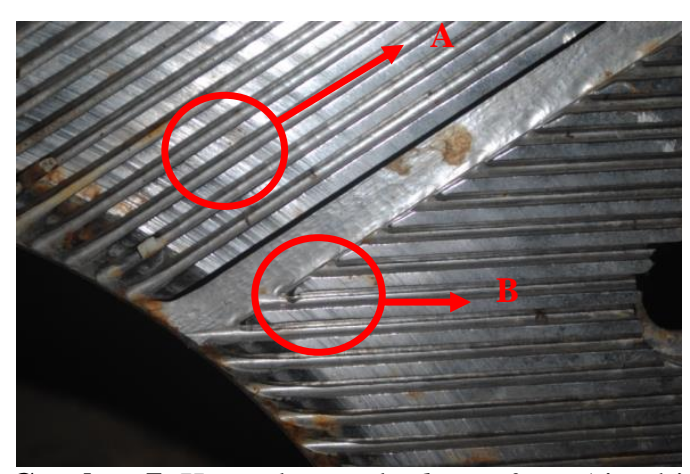

Gambar 7. Kerusakan pada disc refiner Airaghi

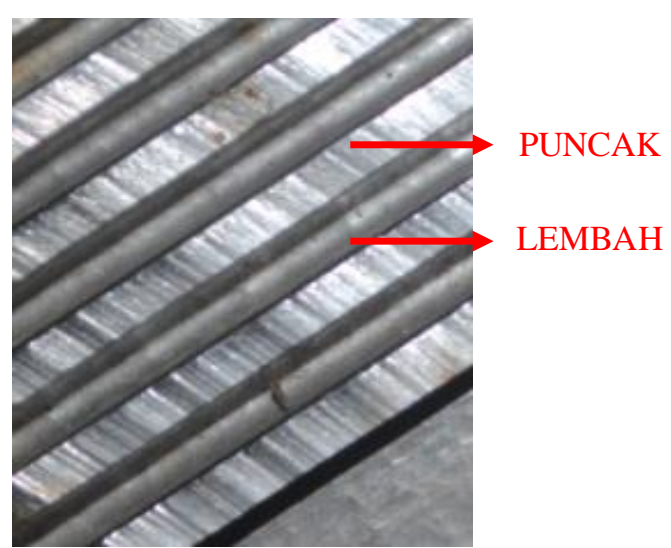

Gambar 8. Detail A kerusakan Serration pada disc refiner Airaghi 


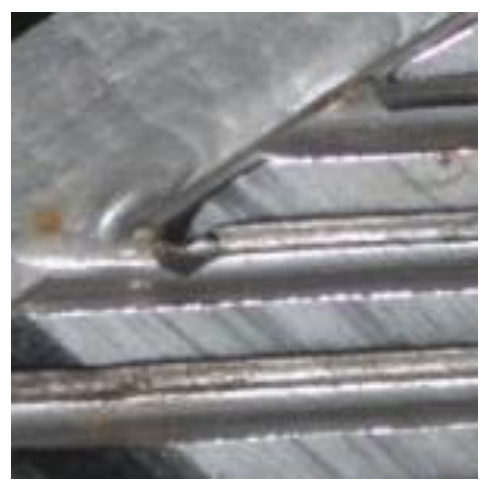

Gambar 9. Detail B kerusakan bengkok pada disc refiner Airaghi

Kerusakan serration terjadi gesekan melingkar di sekeliling disc (Gambar 8) disebabkan abrasive antara pulp dengan material disc dan antar material disc, dengan semakin tingginya kandungan pulp dibandingkan dengan kandungan air (high consistancy) akan semakin memperburuk keausan yang terjadi.

\section{KESIMPULAN}

Dari data yang telah ditampilkan dalam tulisan ini dapat dilihat bahwa material Airaghi terbuat dari stainless stell ASTM A487 dengan kandungan material tertulis diatas.

Dengan kerusakan yang sebagian besar serration dan deformasi plastis/ kerusakan bengkok akibat terbetur benda tumpul, diperlukan kebersihan yang lebih pada penyaringan pulp, terutama dari kotoran pasir.

\section{REFERENSI}

\section{Jurnal:}

[1] Technical group, J\&L fiber services, -, "Optima Technical Bulletin : Heat Treating Refiner Plates" vol V no 1.

[2] Technical group, J\&L fiber services, -, "Optima Technical Bulletin : Diagnosing Refiner Plate Failure Modes in Thermo-Mechanical Pulping" vol 1 no 2.

\section{Buku:}

[1] Anonymous, 2003, "A 487/A 487M-93: Standard Specification for Steel Castings Suitable for Pressure Service" ASTM International, United States

[2] Anonymous, edisi 10, "Welding and Related Processes for Repair and Maintenance Onboard: Maritime Welding Handbook”, Barwil Unitor Ships Service, Noway.

[3] Anonymous, edisi 10, 1993, "ASM Handbook vol 1: Properties and Selection” ASM Internasional

[4] Christopher J. Biermann, 1996, " Pulping and papermaking” Academic press, Oregon

Buku Tesis:

[1] Yuding Jia, 1996, “Failure Analysis \& Material Evaluation of TMP Refiner Plate”UMI company, US Paten:

[1] Matthew, 1975, “Pulp Refiner Elemant” U.S. Patent No. 3,880,368.

\section{Situs:}

[1] Anonymous, "RI Produsen Pulp dan Kertas Terbesar Ke-9 di Dunia," www.duniaindustri.com, diakses: 16 November 2011.

\section{UCAPAN TERIMA KASIH}

Terima kasih penulis sampaikan kepada Bowo Artanto, vice manager paper mill PT. Pura Nusa Persada Kudus yang telah memberikan data dan specimen sehingga kami mampu melakukan penelitian ini. 